\title{
THIS DISAPPEARANCE
}

Can you feel anything here? Here?

How about over here? Here?

I want to be a cobra relaxed on his back in bed, I'd like to be a cobra

in the sink, I'd like to consider

the cobra's long life. Instead, I fill

a glass with water, place it on the table, sit down, and wait for it to evaporate.

I wait 5, 6, 7 days-this disappearance is too subtle! In Iceland or Greenland,

large chunks of glaciers break off, fall into the sea, and float south. Not far

from Rio de Janeiro, slivers of ice begin to wash up onto the beaches.

Again!-this disappearance is too subtle. I want irredeemable proof: let me touch

your cheek. Listen to me: I've given up my right to silence, my right

to decipher these braille instruments.

Can you feel anything here? How about here?

This disappearance between dust and ashes. 